OPEN ACCESS

Edited by:

Yuri Bozzi,

University of Trento, Italy

Reviewed by:

José A. Alda,

Hospital Sant Joan de Deu Barcelona,

Spain

Deepak Kumar

Institute of Human Behavior and Allied

Sciences, India

*Correspondence:

Sara Calderoni

sara.calderoni@inpe.unipi.it

Specialty section:

This article was submitted to

Child and Adolescent Psychiatry,

a section of the journal

Frontiers in Neuroscience

Received: 19 May 2016

Accepted: 11 July 2016

Published: 22 July 2016

Citation:

Billeci L, Calderoni S, Conti E, Gesi C, Carmassi C, Dell'Osso L, Cioni G,

Muratori F and Guzzetta A (2016) The Broad Autism (Endo)Phenotype:

Neurostructural and Neurofunctional

Correlates in Parents of Individuals

with Autism Spectrum Disorders.

Front. Neurosci. 10:346.

doi: 10.3389/fnins.2016.00346

\section{The Broad Autism (Endo)Phenotype: Neurostructural and Neurofunctional Correlates in Parents of Individuals with Autism Spectrum Disorders}

\author{
Lucia Billeci ${ }^{1}$, Sara Calderoni ${ }^{2 *}$, Eugenia Conti ${ }^{1,3}$, Camilla Gesi ${ }^{1}$, Claudia Carmassi ${ }^{1}$, \\ Liliana Dell'Osso ${ }^{1}$, Giovanni Cioni ${ }^{1,2}$, Filippo Muratori ${ }^{1,2}$ and Andrea Guzzetta ${ }^{1,2}$ \\ ${ }^{1}$ Department of Clinical and Experimental Medicine, University of Pisa, Pisa, Italy, ${ }^{2}$ IRCCS Stella Maris Foundation, Pisa, Italy, \\ ${ }^{3}$ Department of Sciences for Health Promotion and Mother and Child Care G. D'Alessandro, University of Palermo, Palermo, \\ Italy
}

Autism Spectrum Disorders (ASD) are a set of neurodevelopmental disorders with an early-onset and a strong genetic component in their pathogenesis. According to genetic and epidemiological data, ASD relatives present personality traits similar to, but not as severe as the defining features of ASD, which have been indicated as the "Broader Autism Phenotype" (BAP). BAP features seem to be more prevalent in first-degree relatives of individuals with $A S D$ than in the general population. Characterizing brain profiles of relatives of autistic probands may help to understand ASD endophenotype. The aim of this review was to provide an up-to-date overview of research findings on the neurostructural and neurofunctional substrates in parents of individuals with ASD (pASD). The primary hypothesis was that, like for the behavioral profile, the pASD express an intermediate neurobiological pattern between ASD individuals and healthy controls. The 13 reviewed studies evaluated structural magnetic resonance imaging (MRI) brain volumes, chemical signals using magnetic resonance spectroscopy (MRS), task-related functional activation by functional magnetic resonance imaging (fMRI), electroencephalography (EEG), or magnetoencephalography (MEG) in pASD. The studies showed that PASD are generally different from healthy controls at a structural and functional level despite often not behaviorally impaired. More atypicalities in neural patterns of pASD seem to be associated with higher scores at BAP assessment. Some of the observed atypicalities are the same of the ASD probands. In addition, the pattern of neural correlates in PASD resembles that of adult individuals with ASD, or it is specific, possibly due to a compensatory mechanism. Future studies should ideally include a group of pASD and HC with their ASD and non-ASD probands respectively. They should subgrouping the PASD according to the BAP scores, considering gender as a possible confounding factor, and correlating these scores to underlying brain structure and function. These types of studies may help to understand the genetic mechanisms involved in the various clinical dimension of ASD.

\footnotetext{
Keywords: Autism Spectrum Disorders, parents, Broader Autism Phenotype, magnetic resonance imaging, magnetic resonance spectroscopy, electroencephalography, magnetoenchephalography
} 


\section{INTRODUCTION}

Autism Spectrum Disorders (ASD) are a set of early-onset neurodevelopmental disorders that are characterized by a disrupted development of brain connectivity with several cascading effects on neuropsychological functions (Narzisi et al., 2013; Kana et al., 2014). A clinical dyad, comprising social communication difficulties and repetitive, stereotyped behavior must be present for a diagnosis of ASD (American Psychiatric Association, 2013). The exact cause of ASD is still unknown (Levy et al., 2009). Although, only $20 \%$ of ASD cases can be explained by a specific genetic cause, such as identifiable genetic syndromes, genetic mutations or de novo copy number variants (Jeste and Geschwind, 2014), recent twin studies estimate an heritability between 64 and 91\% (Tick et al., 2016), suggesting an interaction between genetic vulnerability and environmental factors (Rossignol et al., 2014).

Genetic epidemiological data suggest that personality traits similar to, but not as severe as those of ASD, are also heritable (Freitag, 2007). This group of "sub-threshold" features, which are believed to be milder manifestations of ASD (Dell'Osso et al., 2016), have been indicated as the broader autism phenotype (BAP) (Piven et al., 1997). BAP includes peculiar social, communication, and cognitive processes, strong persistent interests, and rigid and aloof personality traits (Gerdts and Bernier, 2011; Sucksmith et al., 2011). Interestingly, it was shown that BAP traits are more prevalent in first-degree relatives of individuals with ASD than in other groups, supporting the hypothesis that ASD have a significant genetic component (Bailey et al., 1998; Losh et al., 2008).

Kanner and Asperger were the first to report behavioral features in parents that were similar in kind to those of their autistic offspring. In particular, Kanner (1943) observed that both first and second degree relatives of children with "early infantile autism" had common characteristics of late speech, mild obsessiveness and uninterest in people. Similarly, Asperger (1944) described a group of parents of children with autism as withdrawn, pedantic, eccentric, and loners, who had problems relating to the outside world. Later studies have shown that the expression of ASD traits in relatives concerns not only behavioral traits, but also social cognition abilities (e.g., BaronCohen and Hammer, 1997), neurocognitive functioning (e.g., Koczat et al., 2002) or biological dimensions (e.g., Lainhart et al., 2006) and that these aspects could relate to or explain the clinical presentation of the BAP.

The biological dimension of ASD has been largely investigated in the last decades, thanks to the growing availability of brain imaging techniques and analysis methods for in vivo examination of brain structure and function. All in all, these studies reported abnormal neuroanatomical and neurofunctional profiles in individuals with ASD, suggesting a dysfunction of key brain areas underlying the core impairments of ASD (Amaral et al., 2008; Bellani et al., 2013a,b; Billeci et al., 2013; Calderoni et al., 2014). As such, there has been great interest in evaluating whether these neurological profiles also characterize the relatives of autistic probands. Indeed, should the same brain abnormalities of ASD patients be present in their direct relatives, their heritable origin would be strongly supported together with their role as endophenotypes of the disorder (Sullivan et al., 2003; Palmen et al., 2005a). This is particularly true for studies exploring correlations in parents. In fact, while sibling and twin studies are suitable for detecting brain abnormalities under genetic control, studies on parents allow mitigating the role of the shared (preand perinatal) environment (Sullivan et al., 2003; Palmen et al., 2005a). Thus, if brain abnormalities are observed in parents, they are more likely to be of heritable origin and consequently reflect endophenotypes of the disorder. To assess the strength of this hypothesis, we provide here a critical revision of all studies exploring the neuroanatomical and neurofunctional profile of parents of individuals with ASD.

\section{METHODS}

To find papers concerning neuroimaging studies in parents of individuals with ASD, a sensitive search strategy was conducted in two relevant article databases: PubMed and ScienceDirect. Search terms included database subject headings for the concepts of pervasive developmental disorders (e.g. "autism," "autism spectrum disorder," "pervasive developmental disorders"), neuroimaging (e.g., "MRI," "MRS," "EEG," "MEG") and parents ("parents," "relatives," "fathers," "mothers," "broader phenotype"). The reference lists of the retrieved papers were searched to identify additional articles.

Studies adhering to the following criteria were incorporated in this review: (1) parents of individuals with ASD were the population under study; (2) Magnetic Resonance Imaging (MRI), Magnetic Resonance Spectroscopy (MRS), Electroencephalography (EEG) and Magnetoencephalography (MEG) were used to investigate neurostructural and neurofunctional correlates in parents of individuals with ASD; (3) empirical findings about neural substrates were reported by the authors; (4) studies were published before March 30, 2016; (5) studies were published in an English peer-reviewed journal.

\section{RESULTS}

Thirteen published studies meeting the inclusion criteria were identified. Table 1 summarizes the studies included in this review.

\section{Structural MRI}

Only three studies used sMRI to assess brain structure in parents of autistic probands.

Rojas et al. (2004) assessed total brain, hippocampus, and amygdala volumes in adults with ASD, parents of children with ASD (pASD) and healthy controls (HC), defined as adults with no personal or familial history of ASD. The left hyppocampus was found significantly larger in the ASD group in comparison to both the pASD and the HC group, and in the PASD group in comparison to the $\mathrm{HC}$ group. In the three groups, hyppocampus enlargement was more pronounced in males than in females. The right amygdala was smaller in the ASD group in comparison 
TABLE 1 | Neuroanatomical and neurofunctional characteristics associated to the BAP in the parents of individuals with ASD.

\begin{tabular}{|c|c|c|c|c|c|}
\hline Study (year) & $\begin{array}{l}\text { Participants (nr, M/F, mean } \\
\text { age } \pm S D \text { in years) }\end{array}$ & $\begin{array}{l}\text { BAP } \\
\text { Questionnaires }\end{array}$ & Method & Results & $\begin{array}{l}\text { Correlations with BAP } \\
\text { scores and behavior }\end{array}$ \\
\hline \multicolumn{6}{|c|}{ STRUCTURAL STUDIES } \\
\hline & 17 pASD (15/2) $44.75 \pm 4.4$ & & & & \\
\hline Palmen et al., 2005a & 38 pASD (19/19) $50.3 \pm 3.4$ & $A Q$ & $\begin{array}{l}\mathrm{ROI} \\
\text { semi-automatic } \\
\text { tracing }\end{array}$ & $\begin{array}{l}\text { No significant differences in } \\
\text { volume }\end{array}$ & $\begin{array}{l}\text { Positive correlations between } \\
\text { AQ scores and intracranial } \\
\text { and ventricular volume in } \\
\text { pASD }\end{array}$ \\
\hline
\end{tabular}

$40 \mathrm{HC}(20 / 20) 52.0 \pm 4.1$

Peterson et al., $2006 \quad 23$ pASD (8/15) $39.6 \pm 6.0 \quad$ None VBM

$23 \mathrm{HC}(8 / 15) 38.3 \pm 6.4$

\section{fMRI STUDIES}

Baron-Cohen et al. 2006

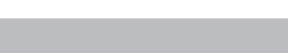

$\begin{array}{ll}12 \text { pASD (6/6) M: } 39.1 \pm 6.0 \quad \text { None } & \text { Visual Search Task } \\ & \\ & \text { (EFT) and Emotion } \\ & \text { Recognition Task } \\ & (E T)\end{array}$
pASD > HC in several GM regions (i.e. right precentral gyrus, right superior parietal lobule, and superior temporal gyri)

$\mathrm{pASC}<\mathrm{HC}$ anterior portion of the left cerebellar hemisphere
F: $37.3 \pm 5.9$
$12 \mathrm{HC}(6 / 6) \mathrm{M}: 23.1 \pm 0.6$
F: $21.6 \pm 0.8$

$\begin{array}{lll}\text { Greimel et al., } 2010 \quad 15 \text { ASD (15/0) } 14.9 \pm 1.6 \quad \text { AQ } & \begin{array}{l}\text { Empathy: } \\ \text { other-task and } \\ \text { self-task }\end{array}\end{array}$

$\mathrm{pASD}<\mathrm{pHC}$ AMY other-task

Females $>$ Males $>$ Fathers $=$ Mothers in BA 19 in EFT task Females $>$ Males $>$ Fathers $=$ Mothers in BA 21 e BA 44 in ET task pASD

F: $37.3 \pm 5.9$
12 HC (6/6) M: $23.1 \pm 0.6$
F: $21.6 \pm 0.8$

$15 \mathrm{HC}(15 / 0) 15.0 \pm 1.4$

11 pASD (11/0) $43.9 \pm 5.1$

pASD $<$ pHC FG other-task $A S D<H C F G$ other-task and self-task

Positive correlation between FG activation and GEM score in ASD

ASD $<H C$ IFG self-task

No significant correlations between brain activity and $A Q$ scores

Positive correlation between insula activation and BEES score in pASD and pHC

$9 \mathrm{pHC}(9 / 0) 47.7 \pm 5.3$

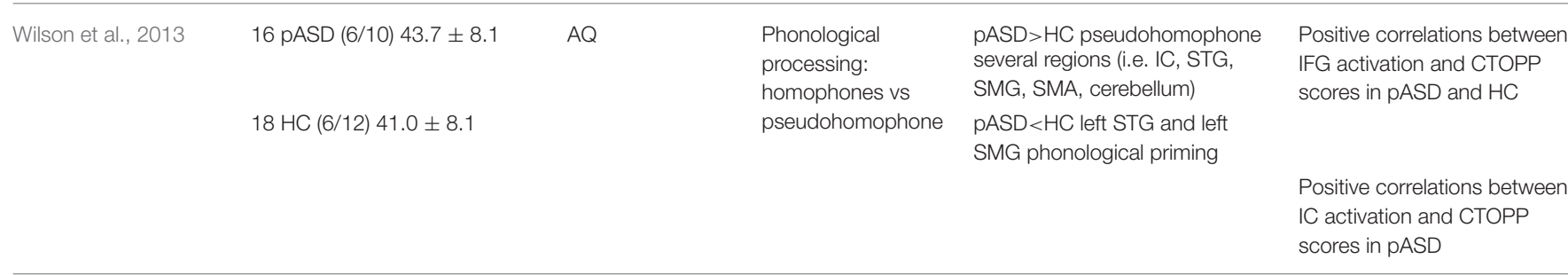

(Continued) 


\section{TABLE 1 | Continued}

\begin{tabular}{|c|c|c|c|c|c|}
\hline Study (year) & $\begin{array}{l}\text { Participants (nr, M/F, mean } \\
\text { age } \pm \text { SD in years) }\end{array}$ & $\begin{array}{l}\text { BAP } \\
\text { Questionnaires }\end{array}$ & Method & Results & $\begin{array}{l}\text { Correlations with BAP } \\
\text { scores and behavior }\end{array}$ \\
\hline \multirow[t]{6}{*}{ Yucel et al., 2014} & 40 pASD (20/20) $40.6 \pm 0.7$ & BAPQ & Face processing & $\mathrm{pASD}>\mathrm{HC} \mathrm{AMY}$ & $\mathrm{BAP}+>\mathrm{BAP}-, \mathrm{HC}$ LOC \\
\hline & & MPAS-R & & & \\
\hline & & & & $\mathrm{pASD}>\mathrm{HC} F G$ & \\
\hline & $15 \mathrm{BAP}+40.9 \pm 1.4$ & & & $\mathrm{pASD}<\mathrm{HC}$ INS & \\
\hline & 25 BAP $-42.1 \pm 1.28$ & & & & \\
\hline & $20 \mathrm{HC}(6 / 12) 39.8 \pm 1.6$ & & & & \\
\hline \multicolumn{6}{|l|}{ MRS STUDIES } \\
\hline \multirow[t]{4}{*}{ Brown et al., 2013} & 13 ASD (9/4) $41.2 \pm 6.9$ & $A Q$ & $\begin{array}{l}\text { Level of Glu, NAA, } \\
\text { Cr in auditory } \\
\text { cortex }\end{array}$ & ASD>HC Glu, NAA, Cr & $\begin{array}{l}\text { Positive correlation, } \\
\text { uncorrected for multiple } \\
\text { comparisons, between left } \\
\text { NAA and the SRS and left } \\
\text { Glu and the AQ }\end{array}$ \\
\hline & & SRS & & $\begin{array}{l}\text { No differences between pASD } \\
\text { and } \mathrm{ASD} \text { or } \mathrm{HC}\end{array}$ & \\
\hline & 15 pASD (11/4) $41.0 \pm 8.1$ & & & & \\
\hline & $15 \mathrm{HC}(6 / 9) 41.1 \pm 6.8$ & & & & \\
\hline \multicolumn{6}{|c|}{ EEG AND MEG STUDIES } \\
\hline Dawson et al., 2005 & 21 pASD (10/11) $38.5 \pm$ n.d. & None & $\begin{array}{l}\text { Face processing } \\
\text { ERPs }\end{array}$ & $\begin{array}{l}\mathrm{pASD}<\mathrm{HC} \text { N170 right } \\
\text { amplitude to faces }\end{array}$ & $\begin{array}{l}\text { Positive correlation between } \\
\text { N170 amplitude to faces and } \\
\text { WMS Immediate and Delay } \\
\text { task in HC }\end{array}$ \\
\hline
\end{tabular}

$\mathrm{pASD}<\mathrm{HC}$ N170 latency

$21 \mathrm{HC}(8 / 13) 38.9 \pm$ n.d.

\begin{tabular}{|c|c|c|c|c|c|}
\hline \multirow[t]{6}{*}{ Rojas et al., 2008} & 11 ASD (9/2) $42.6 \pm 5.1$ & None & $\begin{array}{l}\text { Auditory } \\
\text { stimulation }\end{array}$ & $\mathrm{pASD}, \mathrm{ASD}>\mathrm{HC}$ induced tGBR & - \\
\hline & & & $\begin{array}{l}\text { Evoked, induced } \\
\text { and total power } \\
\text { tGBR }\end{array}$ & $\begin{array}{l}\mathrm{pASD}, \mathrm{ASD}<\mathrm{HC} \text { evoked tGBR, } \\
\mathrm{PLF} \text {, anterior-posterior } \\
\text { asymmetry }\end{array}$ & \\
\hline & 16 pASD (9/7) $31.5 \pm 9.3$ & & & & \\
\hline & & & PLF tGBR & $\begin{array}{l}\text { No differences between pASD } \\
\text { and ASD }\end{array}$ & \\
\hline & & & $\begin{array}{l}\text { Source } \\
\text { Localization }\end{array}$ & & \\
\hline & $16 \mathrm{HC}(7 / 9) 43.1 \pm 6.7$ & & & & \\
\hline \multirow[t]{4}{*}{ Rojas et al., 2011} & $21 \mathrm{pASD}(7 / 13) 43.7 \pm 7.3$ & $A Q$ & $\begin{array}{l}\text { Auditory } \\
\text { stimulation }\end{array}$ & $\begin{array}{l}\text { pASD }<\text { HC total and evoked } \\
\text { power, PLF ASSR }\end{array}$ & $\begin{array}{l}\text { Negative correlation between } \\
\text { ASSR PLF and AQ } \\
\text { communication subscale }\end{array}$ \\
\hline & $20 \mathrm{HC}(6 / 15) 43.8 \pm 6.9$ & SRS & $\begin{array}{l}\text { Evoked, induced } \\
\text { and total power } \\
\text { tGBR }\end{array}$ & No differences in tGBR & \\
\hline & & & PLF tGBR & & $\begin{array}{l}\text { Negative correlation between } \\
\text { tGBR and ASSR evoked } \\
\text { power and SRS scores }\end{array}$ \\
\hline & & & $\begin{array}{l}\text { Evoked, induced } \\
\text { and total power } \\
\text { ASSR } \\
\text { PLF ASSR }\end{array}$ & & \\
\hline $\begin{array}{l}\text { McFadden et al., } \\
2012\end{array}$ & 23 pASD (8/15) $35.8 \pm 10.0$ & None & $\begin{array}{l}\text { Language auditory } \\
\text { stimulation }\end{array}$ & $\begin{array}{l}\text { pASD }>\text { HC evoked and total } \\
\text { gamma SMG, LOC }\end{array}$ & $\begin{array}{l}\text { Significant but different } \\
\text { correlations between gamma } \\
\text { or beta activity and language } \\
\text { measures (expressive, } \\
\text { receptive, figurative language } \\
\text { and phonological processing) } \\
\text { in pASD and HC }\end{array}$ \\
\hline
\end{tabular}

(Continued) 


\section{TABLE 1 | Continued}

\begin{tabular}{|c|c|c|c|c|c|}
\hline Study (year) & $\begin{array}{l}\text { Participants (nr, M/F, mean } \\
\text { age } \pm \text { SD in years) }\end{array}$ & $\begin{array}{l}\text { BAP } \\
\text { Questionnaires }\end{array}$ & Method & Results & $\begin{array}{l}\text { Correlations with BAP } \\
\text { scores and behavior }\end{array}$ \\
\hline & & & $\begin{array}{l}\text { Evoked, induced } \\
\text { and total power } \\
\text { gamma and beta }\end{array}$ & $\begin{array}{l}\text { pASD }>\text { HC evoked and total } \\
\text { gamma SMG, LOC }\end{array}$ & \\
\hline & $28 \mathrm{HC}(12 / 16) 38.7 \pm 6.3$ & & & & \\
\hline & & & $\begin{array}{l}\text { PLF gamma and } \\
\text { beta }\end{array}$ & pASD > HC left lateralization & \\
\hline \multirow[t]{6}{*}{ Buard et al., 2013} & 12 ASD (?/?) $28.3 \pm 13.3$ & None & $\begin{array}{l}\text { Picture-naming } \\
\text { task }\end{array}$ & $\begin{array}{l}\text { ASD }<\text { HC high-gamma in right } \\
\text { STG, evoked } \\
\text { high-beta/low-gamma in left } \\
\text { IFG and PLF beta in OCC }\end{array}$ & $\begin{array}{l}\text { No significant correlation } \\
\text { between MEG measures and } \\
\text { language scores }\end{array}$ \\
\hline & 14 pASD (?/?) $37.9 \pm 5.9$ & & & & \\
\hline & & & $\begin{array}{l}\text { Evoked, induced } \\
\text { and total power } \\
\text { gamma and beta }\end{array}$ & $\begin{array}{l}\text { pASD }>\text { HC high-gamma in left } \\
\text { STG and evoked } \\
\text { high-beta/low-gamma in left } \\
\text { FG }\end{array}$ & \\
\hline & $35 \mathrm{HC}(? / ?) 34.2 \pm 11.9$ & & & & \\
\hline & & & $\begin{array}{l}\text { PLF gamma and } \\
\text { beta }\end{array}$ & $\begin{array}{l}\text { ASD }>\text { HC connectivity } \\
\text { between IFG and FG and } \\
\text { between STG and OCC in both } \\
\text { gamma and beta band }\end{array}$ & \\
\hline & & & Granger Causality & & \\
\hline
\end{tabular}

BAP, Broader Autism Phenotype; ASD, Autism Spectrum Disorders; HC, healthy controls; pASD, parents of individuals with ASD; SD, standard deviation.

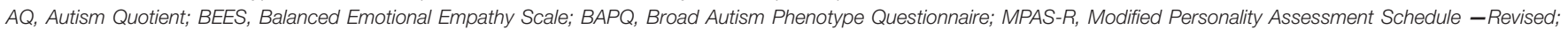
SRS, Social Responsiveness Scale.

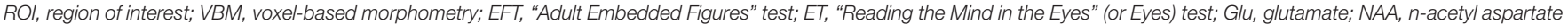

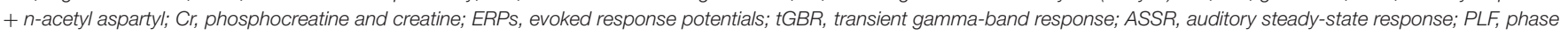
locking factor; CTOOP, Comprehensive Test of Phonological Processing; WMS, Wechsler Memory Scale.

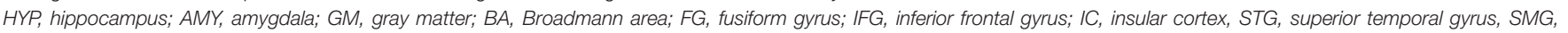
supramarginal gyrus; SMA, supplementary motor area; INS, insula; LOC, lateral occipital cortex; OCC, occipital lobe.

to both the pASD and the HC group, while no significant differences were found between pASD and HC. No differences were detected in the total brain volume among the three groups.

Palmen et al. (2005a) compared couples of pASD with known increased brain volumes with $\mathrm{HC}$ couples for volume differences in total brain, cortical lobes, cerebral and cortical gray matter (GM) and white matter (WM), cerebellum, and ventricles. The overt aim of the study was to investigate whether the cerebral enlargement observed in ASD probands (Palmen et al., 2005b) extended also to parents, and in this case whether fathers and mothers were equally affected and if the same regions, as those of the autistic probands, were interested in the enlargement. The authors found no group or gender differences in any of the brain volumes, including the volume of intracranium, total brain, GM and WM of the cerebrum, frontal, temporal, parietal, and occipital GM and WM, cerebellum, third and lateral ventricle. Nevertheless, within the pASD group significant positive correlations were found between the Autism Quotient (AQ) (Baron-Cohen et al., 2001a) scores and intracranial and ventricular volumes, suggesting that autistic traits might be associated to an enlargement in these structures.
In the third study, Peterson et al. (2006) compared regional GM volume in pASD and in $\mathrm{HC}$, reporting an increase in several GM regions in pASD (e.g., superior temporal gyri, inferior and middle frontal gyri, superior parietal lobule, anterior cingulate). A single large relative decrease was observed in the anterior portion of the left cerebellar hemisphere in pASD compared with HC. Males showed increased GM compared with females in both groups, while no between-group differences respect to gender emerged.

It is worth noting that in the three above mentioned studies three different procedures were applied for data analysis. Specifically, Rojas et al. (2004) used manual tracing for selecting hippocampus and amygdala, Palmen et al. (2005a) applied a semi-automatic procedure to obtain a segmentation of the brain in the structure of interest and Peterson et al. (2006) applied an approach based on voxel-based morphometry (VBM).

\section{Magnetic Resonance Spectroscopy}

Only one study used Magnetic Resonance Spectroscopy (MRS) to assess brain chemistry in parents of individuals with ASD (Brown et al., 2013). The aim of the study was therefore to determine whether the parents of ASD patients show higher 
levels of Glutamate (Hyperglutamate Theory) as compared to controls (Fatemi, 2008). The level of Glutamate (Glu), together with other potentially interesting molecules, including n-acetylaspartate (NAA), choline (Cho), myoinositol (mI) and creatine $(\mathrm{Cr})$, was measured in the auditory cortex of subjects with ASD, pASD and HC. BAP traits in PASD were assessed by AQ and by Social Responsiveness Scale (SRS) (Constantino, 2002). While ASD subjects had increased levels of Glu compared with both pASD and HC, no differences were found between pASD and HC. Although not significantly different, the mean levels of the explored molecules in the pASD group were found to be intermediate between the HC and the ASD group. A significant positive correlation between left NAA and the SRS as well as between left Glu and the AQ was observed, but these correlations did not remain significant after multiple comparison correction. Both ASD and pASD did not exhibit sex differences in any of the MRS measures.

\section{Functional MRI (fMRI)}

The first study that evaluated the BAP in pASD through fMRI technique was performed by Baron-Cohen et al. (2006). In this investigation, the authors used the visual search task "Adult Embedded Figures Test" (EFT) (Witkin et al., 1962), and the advanced emotion recognition task test "Reading the Mind in the Eyes" (or Eyes) (ET) (Baron-Cohen et al., 2001b) in order to see if the parents showed the same atypical brain function observed in the autistic children (Baron-Cohen et al., 1999; Ring et al., 1999). They also preliminarily explored the influence of sex on brain functioning during these two tasks in a small sample of six males and six females. Results indicated that pASD showed atypical brain activity compared with HC; moreover sex differences in neural underpinnings of both tests were found. As far as the EFT task is concerned, pASD showed less activity in the visual cortex while a reduced activity in the mid-temporal gyrus, and the inferior frontal gyrus was observed using the ET task.

As regards sex differences in the EFT, female controls displayed increased activity in middle occipital gyrus than male controls while both mothers and fathers showed even less activity in this area than sex-matched controls. In the ET, female controls exhibited more activity in the left medial temporal gyrus and left dorsolateral prefrontal cortex than male controls, while both mothers and fathers of children with ASD showed a brain activity similar to that of male controls. Mothers and fathers had comparable brain activation. One of the region identified as atypically activated in the ET task (B44) overlaps with a region previously identified as involved in "theory of mind" (Frith and Frith, 1999).

Greimel et al. (2010) explored in ASD boys and in their fathers (pASD) aspects related to the social domain of ASD, and in particular to the mechanism of empathy. Two aspects of empathy were evaluated related to (1) inferring how another person feels (other-task), and (2) responding appropriately to emotions of others (self-task). Comparison groups consist of age-matched typically developing boys (HC) and their fathers $(\mathrm{pHC})$. Brain activation was analyzed in three predefined ROIs, the fusiform gyrus (FG), the inferior frontal gyrus (IFG) and the AMY and correlations with behavioral traits were evaluated.
Empathic abilities were assessed by the Griffith Empathy Measure (GEM) in ASD and by the Balanced Emotional Empathy Scale (BEES) in pASD.

Despite a normal performance in reference to the number of correct/incorrect responses and even a faster response than $\mathrm{pHC}$, pASD showed an abnormal brain activation. Specifically, both boys with ASD and their fathers obtained reduced anterior FG activation during the other-task, and boys with ASD additionally exhibited reduced FG activation during the self-task compared to HC. Interestingly, the activation within the FG occurred outside the well-known fusiform face area leading to exclude that differences of activation detected in this area were ascribable to a deficit in face processing. This hypothesis was corroborated also by the recording of the gaze during the fMRI task that showed an intact gaze pattern in scanning faces both in the adolescents with ASD and in their fathers. A diminished activation was also found in AMY in fathers of boys with ASD compared to control fathers when inferring others' emotions from weak cues, while in the ASD group this result was only obtained at an uncorrected threshold. The author hypothesized that fathers activated strategies to compensate for FG and AMY dysfunction. An involvement of the mirror neuron system (MNS) was also observed mainly in the ASD adolescents who showed a reduced activation of the IFG during the self-task. In both pASD and ASD groups a significant correlation between behavioral measures of empathy and brain activation was detected: specifically, in the ASD group the correlation was significant with activation of FG while in the PASD group with activation of the insula. However, no significant correlation was found between brain activity and AQ scores in pASD.

Together with social impairments, language dysfunction is another well-known hallmark of ASD. Extending the boundaries, language ability, specifically phonological processing ability, has been proposed to be one of six candidate BAP traits (Dawson et al., 2002).

Wilson et al. (2013) explored the neural correlates of phonological processing ability in a group of parents of children with ASD and in a group of age-matched controls. The task proposed consisted of prime-target word pairs differing in terms of their phonological relatedness including both wordword homophone and pseudoword-word pseudohomophone. Brain activation was also correlated with a behavioral measure of phonological processing ability obtained by the non-word repetition subtest of the Comprehensive Test of Phonological Processing (CTOPP) (Wagner et al., 1999).

Despite non-significant differences in terms of task performances and CTOPP scores and low AQ scores, pASD showed significantly higher hemodynamic responses than controls for pseudohomophone compared with homophone priming. Several cortical regions were involved in this abnormal activation, including the left anterior insular cortex (IC), the bilateral cerebellum and thalamus, left postcentral gyrus, precentral gyrus, and supplementary motor area (SMA), right superior temporal gyrus (STG) and supramarginal gyrus (SMG): interestingly, most of these regions had been previously implicated in language processing (Baddeley, 1992; Ackermann and Riecker, 2004; Hickok and Poeppel, 2007; Ghosh et al., 
2008). Significant positive correlations were also observed between greater hemodynamic response and CTOPP in right STG, left IFG and IC in pASD and in several regions in controls (i.e. bilateral occipital gyrus, parietal lobule, postcentral gyrus, lingual gyrus, and IFG).

Moreover, parents of boys with ASD exhibited increased hemodynamic suppression in response to phonological priming compared with controls in several cortical regions including both the left lateralized STG and SMG. Both groups expressed a significant left lateralization in the ROI selected for the analysis.

The more recent fMRI study conducted in parents of individuals with ASD investigated neural substrates of face processing (Yucel et al., 2014). This is the only study which subset the parents on BAP traits. Specifically, in order to investigate the characteristics of a specific endophenotype linked to social behavior, the parents were classified in a group having "aloof personality" (BAP+) and a group having "non-aloof personality" (BAP-). The classification was based on the Broad Autism Phenotype Questionnaire (BAPQ) and the Modified Personality Assessment Schedule-Revised (MPAS-R) specifically designed to determine the presence or absence of "aloof personality." Using two face activation paradigms, one based on face memory and the other based on emotional matching, the authors found that pASD had a higher activation of AMY and FG and a lower activation of right insula compared with $\mathrm{HC}$, while no significant difference in activation was observed between $\mathrm{BAP}+$ and $\mathrm{BAP}-$ in these regions. Conversely, $\mathrm{BAP}+$ and $\mathrm{BAP}-$ parents significantly differ in terms of activation of the lateral occipital cortex (LOC). Indeed, BAP + parents showed a bilateral hyper-activation in the LOC compared with both BAP- and HC.

\section{Neurophysiology (Electroencephalography and Magnetoencephalography)}

The first electrophysiological study in pASD was performed by Dawson et al. (2005) who evaluated event-related brain potentials to face and non-face stimuli. Specifically, upright and inverted faces or chairs were presented to a group of pASD and HC and N170 amplitude and latency was measured at the inferior right and left posterior temporal regions. While HC showed the typical pattern of higher right than left N170 amplitude in response to faces (Bentin et al., 1996), pASD exhibited reduced right N170 amplitude resulting in bilaterally distributed brain activity to faces. In addition, HC had the expected faster N170 response to upright faces compared to upright chairs (Itier et al., 2006), while pASD showed no differences in latency in response to the two types of stimuli. Abnormalities in brain activity in pASD compared to controls were also associated to lower performances in behavioral tests (face recognition and object memory).

Subsequent studies explored brain activity in pASD in response to different stimuli using magnetoencephalography (MEG), focusing on high-frequency bands.

First, Rojas et al. (2008) investigated both evoked and induced components of the transient gamma-band response $(t G B R)$, elicited by auditory stimulation in subjects with ASD, in pASD and in a comparison group of healthy subjects. Source localization of the data was performed on MRI data acquired on the subjects enrolled in the study (Peterson et al., 2006). In addition to evoked and induced power, the authors also computed the phase locking factor (PLF) as a measure of phase consistency across trials.

Both pASD and the ASD groups showed bilaterally higher induced tGBR response compared with controls, while evoked tGBR was found bilaterally reduced in the same comparison. The PLF was also bilaterally reduced in both the pASD and the ASD group compared with HC. Moreover, both the pASD and the ASD group had a reduced anterior-posterior asymmetry of the magnetic sources compared with controls. In this study, no differences between pASD and ASD were found: such findings could be attributable to the low statistical power, but could also suggest that parents had the familial liability relevant to gamma-band disturbances.

Later, Rojas et al. (2011) extended the results of their previous work analyzing not only the tGBR component of gammaband power, but also the auditory steady-state response (ASSR), in response to auditory stimulation. A group of pASD was compared with a control group of HC. In this study, authors also correlated MEG results with scores indicative of BAP-traits (AQ and SRS). The group of pASD exhibited reduced evoked power, total power (left hemisphere) and PLF (left hemisphere) of the ASSR component relative to the HC group. However, the authors were not able to replicate their previous findings relative to tGBR (Rojas et al., 2008), as they did not found any significant differences between $\mathrm{pASD}$ and HC.

Interestingly, an inverse correlation between ASSR PLF and the AQ communication subscale was found in pASD, confirming an association of gamma-band activity to perception of speech sounds and lexicality (Kaiser, 2004; Basirat et al., 2008). An inverse correlation was also observed in pASD between SRS scores and tGBR and ASSR gamma-band evoked power suggesting an indirect relationship between auditory gammaband dysfunction and social traits of ASD.

In another investigation (McFadden et al., 2012), gammaband response was analyzed in pASD and in $\mathrm{HC}$ in response to auditory language stimuli, rather than to simple auditory stimuli. In this contest, beta band activity was also examined since it has been suggested to be involved in language processing (Shahin et al., 2009). While in the previous two investigations (Rojas et al., 2008, 2011) pASD showed decreased evoked gamma-band response compared with $\mathrm{HC}$, in this study pASD exhibited increased evoked power. In addition, there was an increase in pASD of total gamma power compared with controls. Source localization analysis showed that this increase was mainly localized in the SMG, in the lateral occipital cortex (LOC), and in the FG.

Beta evoked activity was also found increased in pASD compared with controls mainly in SMG, but also in LOC and FFG possibly reflecting differences in cognitive function during language processing. While in both groups the task generally elicited left lateralized responses, pASD showed greater left lateralization than controls, confirming also in this case an atypical lateralization of the brain in pASD. Significant but different correlations were found between gamma or beta band activity and language measures. 
Gamma and beta band responses were also assessed in pASD compared with HC during a picture-naming task (Buard et al., 2013). Subjects were instructed to sub-vocalize (to reduce motion artifacts) the name of the object depicted in the image they were shown. Due to their involvement in language function and in visual processing, FG, STG, IFG and occipital lobe (OCC) were considered as the regions of interest. As in the three previous studies (Rojas et al., 2008, 2011; McFadden et al., 2012), evoked and induced power together with PLF were computed. In addition, Granger causality function, as a measure of effective connectivity among the activated regions, was measured.

Interestingly, the ASD group and the pASD showed different patterns of activation both in gamma and beta bands. While the ASD group exhibited reduced evoked high-gamma activity in the right STG, increased evoked high-beta/low-gamma in the left IFG and reduced PLF beta in the OCC, the pASD group showed increased evoked high-gamma in the left STG and evoked highbeta/low-gamma in the left FG.

Functional connectivity abnormalities were only observed in the ASD group compared with the control group: specifically, over-connectivity was found in the left hemisphere between IFG and FG and between STG and OCC in both gamma and beta band. This altered functional connectivity from anterior to posterior language and visual areas may partially explain the impaired activation of these regions in the ASD group, ascribable to alterations in long-range neural synchronization.

\section{DISCUSSION}

The main leading hypothesis tested in this review is that pASD present with a number of neuroanatomical and neurofunctional characteristics observed in individuals with ASD, but to a lesser extent. This hypothesis is supported by previous studies demonstrating intermediate levels of biochemical, immunological, morphological and neuropsychological endophenotypes/biomarkers in pASD (Ruggeri et al., 2014).

In some cases, the results of the studies, using different methodological approaches, have supported the primary hypothesis, while in other cases different results have emerged.

\section{Are pASD Different from HC?}

All of the 13 reviewed studies compared the pASD with a sample of $\mathrm{HC}$.

(a) No differences in total brain volumes between pASD and controls were found in any of the three sMRI studies (Rojas et al., 2004; Palmen et al., 2005a; Peterson et al., 2006). This finding is not surprising when considering that even within the ASD population many/most adults, unlike children, do not differ from controls in overall brain volume. Indeed, there is increasing evidence that brain growth trajectory is abnormal in subjects with ASD and that they have differences in the timing of both initiation and cessation of overall brain growth, resulting in larger brain volumes during childhood followed by later normalization (Courchesne et al., 2001, 2003; Dawson et al., 2007). (b) More inconsistent findings were reported for the single brain structures. While Palmen et al. (2005a) found no differences between pASD and $\mathrm{HC}$ groups in any of the volumes considered, including cortical lobes, cerebral GM and WM, cerebellum, and ventricles, increased volumes were found in the left hippocampus (Rojas et al., 2004) or in a number of GM regions (Peterson et al., 2006). The different approach in analyzing brain regions (global brain structures-Palmen et al., 2005a-vs. focal structures-Rojas et al., 2004-vs. whole brain approach-Peterson et al., 2006) prevents a comparison among studies. Overall, the inconsistency of these results reflects that of the studies on subjects with ASD (Ameis and Catani, 2015). Methodological differences between investigations and the potential for heterogeneity of underlying brain alterations in ASD likely contribute to the inconsistency of these results.

(c) Functional studies showed some atypicalities in face processing, empathy and language/auditory processing in pASD compared with HC.

\section{Face}

The study by Dawson et al. (2005) support the social motivation impairment showing an abnormal N170 response to faces both in its latency and amplitude with a pattern resembling that observed for subject with ASD (Apicella et al., 2013). Yucel et al. (2014) observed an increased activation in pASD compared with controls during an emotion recognition task in regions that are specialized for face processing, i.e., the fusiform gyrus and the amygdala.

\section{Empathy}

An opposite pattern was found by Greimel et al. (2010) who explored empathy during the presentation of emotional stimuli in $\mathrm{pASD}$ and found a decreased activation in the same regions. It is possible that the two different types of task lead to different brain activations. Moreover, the different results could be explained by the fact that the sample of Greimel study is composed of males only who are generally less empathic than females (Klein and Hodges, 2001), and therefore process emotion to a lesser extent than females. In addition it is worth noting that Yucel et al. (2014) found a decreased activation of the insula, which is known to be linked to empathic abilities (Carr et al., 2003) as also suggested by the positive correlation found in Greimel et al. (2010) between insula activation and the BEES. Emotion recognition impairments in pASD also emerged from the study of Baron-Cohen et al. (2006) who observed a decreased activation in the left IFG of pASD compared with controls during an emotion recognition test.

\section{Language}

Wilson et al. (2013) showed that pASD compared with HC exhibit a greater hemodynamic response to pseudohomophones respect to homophones and an enhanced hemodynamic suppression in response to phonological priming. Interestingly, Peterson et al. (2006) observed both cerebellar enhancements and reductions, although in different cerebellar regions than those differently activated in the phonological task, and larger left STG 
and SMG GM volumes in pASD relative to HC. These regions are known to be involved in language and phonological processing (Turkeltaub and Coslett, 2010) and to be functionally impaired in ASD (Mostofsky et al., 2009).

Abnormalities associated to language processing have been shown also by MEG studies, mainly associated to gamma-band response. In particular, gamma-band deficit, which has been suggested as a biomarker of ASD (Jamal et al., 2013; Rojas and Wilson, 2014), exists also in pASD, and abnormalities seem to extend also to the beta band. In ASD individuals, dysfunctional gamma-band response has been associated with GABAergic inhibitory deficits (Hussman, 2001; Fatemi et al., 2009). Conversely, multiple evidences suggest an increased neuronal excitability in ASD, involving a higher than normal serum glutamate (Shinohe et al., 2006), and increased metabotropic glutamate receptor expression (Fatemi et al., 2011). Overall, these evidences have been summarized in the excitation/inhibition imbalance (EI) theory of ASD (Rubenstein and Merzenich, 2003).

Rojas et al. $(2008,2011)$ explored gamma band response to auditory stimulation in pASD. Induced response has been found increased in pASD (Rojas et al., 2008), while evoked response and PLF were decreased (Rojas et al., 2011) compared with HC in response to simple auditory stimulus. However, more complex stimuli activate a different pattern as observed in subsequent investigations (McFadden et al., 2012; Buard et al., 2013). In both these studies, pASD showed an increased evoked gamma band response compared with $\mathrm{HC}$, which extended also to beta band in Buard et al. (2013). The different findings among these studies might be explained by the different level of complexity of the tasks: specifically, subjects were requested to be engaged in higher order cognitive processes including language and sustained attention (McFadden et al., 2012; Buard et al., 2013), or only passive listening to a simple auditory stimulus was required (Rojas et al., 2008, 2011).

The studies exploring auditory/language processing suggest that when pASD are involved in higher cognitive function they activate a higher brain response compared to that of controls, possibly as a compensatory mechanism in absence of behavioral impairment. In the study by Wilson et al. (2013) the greater hemodynamic responses in the parent group might reflect the heavier demands requested by the pseudohomophone primes on phonological recoding and working memory skills compared with homophone primes, and it can be interpreted as an index of more effortful processing during this task. Analogously, in the studies by McFadden et al. (2012) and Buard et al. (2013) the increase in gamma and/or beta could reflect a greater cognitive effort in phonology and receptive language tasks, which determine an abnormal synchronous activation of language networks (Jerbi et al., 2009).

It is worth noting that functional abnormalities at a neural level in pASD are not always associated to behavioral impairments. For example Greimel et al. (2010) found a non-compromised empathic ability in an emotion recognition task while Wilson et al. (2013) found no difference in terms of phonological processing (CTOPP scores) between pASD and HC. Conversely in the study by Dawson et al. (2005) the authors found that neurofunctional abnormalities and neuropsychological performances in pASD were associated, suggesting that pASD are more compromised at a neural level than at a behavioral level.

\section{How Are Parents of Individuals with ASD Compared to Other Individuals with ASD?}

Only five of the 13 studies addressed the question of the overlap between pASD and other individuals with ASD (Rojas et al., 2004, 2008; Greimel et al., 2010; Brown et al., 2013; Buard et al., 2013). All reported similarities in some aspects of brain structure and function consistent with the hypothesis of a continuum of some ASD features expressed in pASD, with milder but qualitatively similar brain alterations to those detected in ASD.

In particular, structural (Rojas et al., 2004) and spectroscopy (Brown et al., 2013) studies revealed a brain endophenotype in pASD intermediate between ASD patients and HC. Specifically, Rojas et al. (2004) found that hippocampus enlargement interested also pASD, but to a lesser extent than ASD individuals. Vice-versa, the amygdala was smaller in ASD patients compared to pASD. Brown et al. (2013) showed that the mean levels of the explored molecules in the parent group were intermediate between ASD individuals and HC. However, these findings were not statistically significant possibly due to the small sample size and/or to the low scores at the AQ and the SRS of the pASD subjects.

The fMRI study exploring the neural correlates of empathy (Greimel et al., 2010) reported a reduced activation in the right anterior fusiform gyrus in both adolescents with ASD and pASD compared to age and IQ matched controls. Finally, using EEG a reduced early auditory gamma-band response shared by both adults with ASD and pASD in comparison to HC was detected (Rojas et al., 2008).

Several other patterns of brain activity were not shared by pASD and ASD patients, potentially suggesting a lesser role of these aspects as endophenotypes of the disorder. For example, in the same fMRI study exploring empathy (Greimel et al., 2010), reduced amygdala activity was found in pASD but not in ASD. Also, using MEG during a picture naming task, Buard et al. (2013) found that gamma-band activity showed opposite profiles in pASD and in ASD subjects relative to controls, being increased in the former and reduced in the latter.

All in all, the limited number of studies addressing this question does not allow for definitive conclusions although it seems to be conceivable that some aspects of brain structure and function are shared by pASD and ASD patients, supporting their possible role as endophenotype of the disorder.

\section{How Are Parents of Individuals with ASD Compared to Their Probands?}

The study by Greimel et al. (2010) was the only one that enrolled both the probands and their fathers to explore the transmission of neural substrates. The results confirmed the primary hypothesis of a neurofunctional pattern in pASD intermediate between $\mathrm{HC}$ and ASD. In particular, pASD showed an abnormal neural activation during the other-task similar to their probands, 
expressed by a reduced hemodynamic response in FG - a tempooccipital brain region primarily involved in face processing-. Conversely, unlike their probands, pASD showed a normal response during the self-task. It is of interest that a reduced activation of regions previously associated to the MNS, namely IFG, was found in ASD probands but not in their fathers. These results support the hypothesis that FG dysfunction in ASD is genetically influenced (Polk et al., 2007).

\section{Are the Neurostructural and Neurofunctional Alterations Reported in Parents of Individuals with ASD Specifically Related to BAP Features?}

Six of the reviewed studies (Palmen et al., 2005a; Greimel et al., 2010; Rojas et al., 2011; Brown et al., 2013; Wilson et al., 2013; Yucel et al., 2014) assessed the BAP characteristics of the pASD applying instruments such as the AQ, the BAPQ or the SRS. Significant correlations between scores at the questionnaires and the brain structural and functional indexes were found in almost all these studies. In particular, Palmen et al. (2005a) found a significant positive correlation between AQ scores and intracranial and ventricular volume in PASD, while Brown et al. (2013) found a significant, uncorrected, positive correlation between left NAA and the SRS and left Glu and the AQ. Both studies did not report significant differences in pASD compared to HC (Palmen et al., 2005a; Brown et al., 2013); however, the fact that pASD scored very low at questionnaires assessing BAP could represent a possible bias leading to negative findings. Interestingly, in both studies a positive correlation between neurostructural results and BAP features was found, suggesting that enlarged brain volume or increased Glu level respectively could still be associated to the autistic phenotype.

Notably, Wilson et al. (2013) found significant differences in brain activation during a language task in the pASD sample, despite low scores at the AQ. This result could suggest that deficits in neural substrates of language processing could be associated with autistic traits, confirming it as one of the core impairment of ASD.

This is confirmed by the investigation of Rojas et al. (2011) in which a negative correlation between ASSR PLF and AQ communication subscale as well as between SRS scores and tGBR/ASSR evoked power was observed. ASSR PLF and evoked power were found decreased in pASD compared to HC: therefore, it can be argued that deficits in auditory gamma band are correlated to problems in communications (AQ) and socials skills (SRS). Despite the authors did not find significant differences regarding tGBR, a significant correlation between SRS scores and this feature was observed in pASD suggesting a possible association with the autistic phenotype, as proposed in their previous study (Rojas et al., 2008).

Greimel et al. (2010) did not find any significant correlation between brain activation and AQ in PASD, while a brainbehavior relationship was detected with empathic scores (BEES).

The paper by Yucel et al. (2014) was the only one subgrouping the parent sample according to BAP traits. Interestingly, the authors observed that while an atypical activation of face processing regions was common to both groups of parents, $\mathrm{BAP}+$, but not BAP - parents showed an hyper-activation of lateral occipital cortex. The hyper-activation of LOC in BAP+ could reflect an aberrant "compensatory" activation of these regions in $\mathrm{BAP}+$ parents. These data suggest that while neural circuitry abnormalities in the regions specific for face processing are necessary for the occurrence of the BAP, they are not sufficient to result in autism-related social behavior.

Overall, these findings suggest a possible link between the subclinical dimension of BAP and neurobiological expression of brain function and structure.

\section{Does Gender Influence Neurostructural and Neurofunctional Results in Parents of Individuals with ASD?}

Previous studies have reported sex differences in brain in healthy populations and these processes have shown to differ in people with ASD. In particular, sexual dimorphism in brain regions that are crucial to language and social abilities has been proposed (Lai et al., 2013; Retico et al., 2016).

Understanding cerebral gender differences is important, among other reasons, to explain the increased vulnerability of males to ASD. Few studies have explored gender differences in pASD in order to investigate the heritability of sex differences in brain structures and function.

From a structural point of view, it was observed that males, both pASD and $\mathrm{HC}$ had increased total, hippocampal and amygdala volumes (Rojas et al., 2004), as well as GM (Peterson et al., 2006) compared to pASD and HC females, but this difference did not contribute to between-groups differences. Brown et al. (2013) investigated gender differences in MRS measures both in ASD and pASD and did not find any differences as well. Conversely, Baron-Cohen et al. (2006) found significant differences in brain function related to gender. In particular, their results support the hypothesis of the "Extreme Male Brain Theory" of ASD, according to which "the male brain is programmed to systemize and the female brain to empathize" (Benenson, 2003). Indeed, both mothers and fathers showed an activation even lower than that of male controls in regions were female controls had a higher activity. The results of this study may suggest a genetic component of the hyper-masculinization of the brain.

\section{Do Parents of Individuals with ASD Express an Atypical Lateralization of the Brain?}

In typical development, lateralization of brain function underlies specialized cognitive and behavioral processes (Mesulam, 1990). In particular, several pieces of evidence exist about a left lateralization in language regions (Knecht et al., 2000), and right lateralization in attentional regions (Corbetta and Shulman, 2011) in the majority of individuals with typical development. Atypical lateralization in brain structure and function has been associated with ASD (Conti et al., 2016); more specifically, reduced left lateralization or reversed lateralization of brain structure and function in core language regions and in the WM tracts that connect them has been shown in ASD using different 
techniques (Kleinhans et al., 2008; Lange et al., 2010; Seery et al., 2013).

Whether the pattern of lateralization related to language processing observed in subjects with ASD is the same in their parents is not clear from the reviewed studies.

In Wilson et al. (2013), hemispheric lateralization analysis did not indicate greater right hemispheric language dominance in the pASD: in fact, both pASD and HC showed left lateralization across the selected ROIs. McFadden et al. (2012) found that pASD showed even an increased left lateralization than controls. Rojas et al. (2011) showed that differences in ASSR response in pASD was restricted to the left hemisphere, however across groups the tGBR and ASSR evoked power was increased in the right hemisphere. Rojas et al. (2008) highlighted a peculiar pattern of asymmetric activation in control subjects in which the activation of the right hemisphere was anterior to that of the left hemisphere. This pattern was not observed in ASD and was mild in $\mathrm{pASD}$.

Yucel et al. (2014), observed in the face processing task a significant effect of hemisphere. Specifically, FG showed greater activation in right than left hemisphere in $\mathrm{BAP}+$ compared with $\mathrm{BAP}-$ and $\mathrm{HC}$, and right amygdala was more active than left in $\mathrm{BAP}+$ compared with $\mathrm{BAP}-$. Since right lateralization was observed specifically in BAP+ pASD, a compensatory mechanism of activation in these regions could be hypothesized for this subgroup of parents. Additional support for this interpretation can be found in the investigation of Rojas et al. (2004) on the basis of which pASD has reduced right amygdala volume compared with $\mathrm{HC}$ : it may be possible that to compensate the reduction of volume an abnormal high activation is required.

\section{CONCLUSIONS AND FUTURE DIRECTIONS}

Although, results are often unclear and contradictory, some general considerations can be done:

(i) pASD differ from $\mathrm{HC}$ both at a structural and functional level and these neural abnormalities are not always associated with behavioral impairments;

(ii) The neural pattern in pASD seems to be intermediate between HC and ASD probands;

(iii) More atypicalities in neural patterns of pASD seem to be associated with higher autistic traits;

(iv) The pattern of neural correlates in pASD resembles that of adult individuals with ASD or it is specific to pASD, possibly due to a compensatory mechanism;

(v) The gender might influence the results.

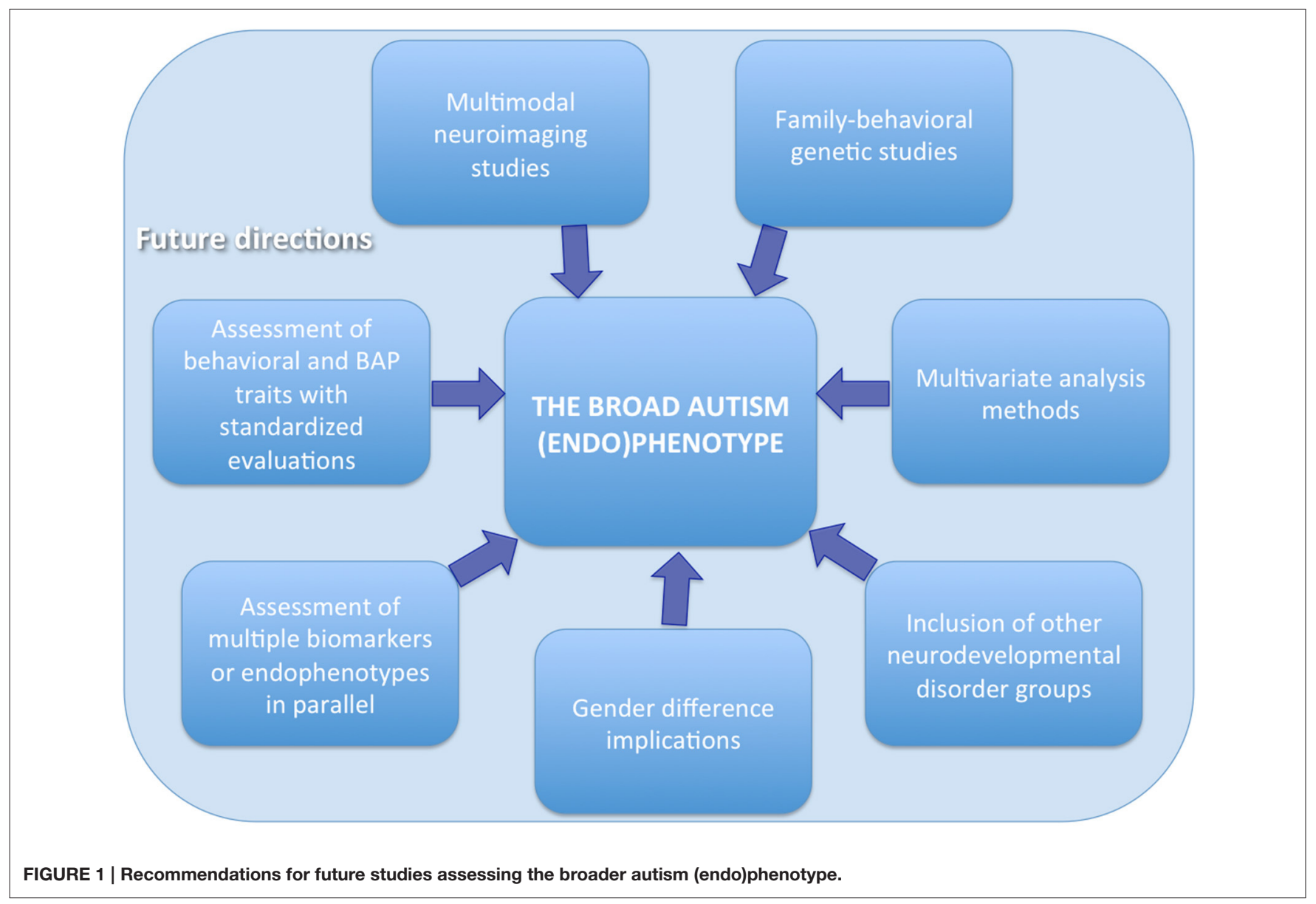


In conclusion, our review reports findings that are often nonreplicated, preventing a univocal interpretation of the results.

In order to elucidate the brain structural and functional underpinnings in pASD and their potential role as endophenotype, several aspects should be considered when planning future studies (Figure 1).

First, neuroimaging studies should be ideally include a group of pASD and HC with their ASD and non-ASD probands, respectively. Second, a family-behavioral genetic design should be adopted in order to analyze the behavioral features as well as the genetics not only of the probands, but also of the parents and the siblings, and to link these data to underlying brain structure and function. Third, behavioral assessment as well as BAP traits evaluation should be performed using standardized questionnaires and tests in order to subgroups the probands and their relatives according to the obtained scores and to investigate a possible correlation between brain abnormalities and BAP traits and/or behavioral impairments. Fourth, multimodal imaging techniques could also be adopted to better elucidate brain correlates of BAP. For example, the integration of neuroimaging data with neurophysiological signals (EEG and MEG) offers advantages of both high spatial and temporal resolution (Ingalhalikar et al., 2012; Berman et al., 2016). The application of these methods also in pASD probands could provide new insights into the endophenotype of ASD. Fifth, since gender can influence neural substrates, this factor needs to be carefully taken into account when grouping samples and interpreting the results. Indeed, brain endophenotypes could be related to differences in the developmental, psychiatric, and medical endophenotypes between males and females with ASD. These research findings may in turn help the clinical assessment and treatment of ASD and the search for possible etiologies (Rubenstein et al., 2015). Sixth, studies on the BAP could also benefit of the assessment of multiple endophenotypes/biomarkers in parallel by collecting, in addition to neuroimaging data, immunological, biochemical, or neuropsychological data and evaluating the cross talk among the different modalities (Ruggeri et al., 2014). Seventh, the inclusion of samples with other neurodevelopmental disorders rather than ASD can help to disentangle the specific from the non-specific endophenotypes associated to each condition.

\section{REFERENCES}

Ackermann, H., and Riecker, A. (2004). The contribution(s) of the insula to speech production: a review of the clinical and functional imaging literature. Brain Struct. Funct. 214, 419-433. doi: 10.1007/s00429-010-0257-x

Amaral, D. G., Schumann, C. M., and Nordahl, C. W. (2008). Neuroanatomy of autism. Trends Neurosci. 31, 137-145. doi: 10.1016/j.tins.2007.12.005

Ameis, S. H., and Catani, M. (2015). Altered white matter connectivity as a neural substrate for social impairment in Autism Spectrum Disorder. Cortex 62, 158-181. doi: 10.1016/j.cortex.2014.10.014

American Psychiatric Association, (2013). Diagnostic and Statistical Manual of Mental Disorders, 5th Edn. Arlington, TX: American Psychiatric Association.

Apicella, F., Sicca, F., Federico, R. R., Campatelli, G., and Muratori, F. (2013). Fusiform gyrus responses to neutral and emotional faces in children with
Indeed brain alterations have been found in relatives of probands with Attention Deficit/Hyperactivity Disorder-ADHD_(Casey et al., 2007; Hale et al., 2010; Poissant et al., 2014; Rapin et al., 2014), language impairments (Plante, 1991; Ors et al., 2002) and learning or intellectual disabilities (Mannerkoski et al., 2009). In particular, previous literature suggests that there are cognitive and brain endophenotypes common to ASD and ADHD and that studying the similarities and differences between these two disorders might be a powerful research approach to increase our understanding of their pathophysiology (Rommelse et al., 2011). Finally the use of multivariate approaches, based for example on machine learning (Retico et al., 2014; Segovia et al., 2014), can provide more insightful results than the traditional statistical analysis methods.

In conclusion, these types of implementations may help to better elucidate the hereditary mechanisms involved in the various clinical dimension of ASD.

\section{AUTHOR CONTRIBUTIONS}

LB performed the literature-search, analyzed the data and drafted the paper, SC, EC made substantial contribution in the literature analysis and in writing the paper, CG, CC collaborated during the literature analysis, LD, GC participated in the design of the paper and supervised the wiring, FM, AG made substantial contributions to the conception of the review, and revisited the manuscript critically. All the authors read and approved the final version of the manuscript.

\section{FUNDING}

The research leading to this work has received funding from the University of Pisa, Bando PRA 2015, Project "Broader autism phenotype: brain connectivity biomarkers from the adult to the child." This work was also supported by grant from the IRCCS Stella Maris Foundation (Ricerca Corrente, and the " $5 \times 1000$ " voluntary contributions, Italian Ministry of Health to SC, GC, FM, AG). SC was supported by the Ministry of Health, Italy and by Tuscany Region with the grant "GR-2010-2317873," and by Bando FAS Salute Sviluppo Toscana -ARIANNA Project.

autism spectrum disorders: a high density ERP study. Behav. Brain Res. 251, 155-162. doi: 10.1016/j.bbr.2012.10.040

Asperger, H. (1944). Die autistischen Psychopathen im Kindersalter. Arch. Psychiatr. Nervenkr. 117, 76-136. doi: 10.1007/BF01837709

Baddeley, A. (1992). Working memory. Science 255, 556-559. doi: $10.1126 /$ science. 1736359

Bailey, A., Palferman, S., Heavey, L., and Couteur, A. L. (1998). Autism: the phenotype in relatives. J. Autism Dev. Disord. 28, 369-392. doi: 10.1023/A:1026048320785

Baron-Cohen, S., and Hammer, J. (1997). Parents of children with asperger syndrome: what is the cognitive phenotype? J. Cogn. Neurosci. 9, 548-554. doi: 10.1162/jocn.1997.9.4.548

Baron-Cohen, S., Ring, H., Wheelwright, S., Bullmore, E. T., Brammer, M. J., Simmons, A. C., et al. (1999). Social intelligence in the normal and autistic 
brain: an fMRI study. Eur. J. Neurosci. 11, 1891-1898. doi: 10.1046/j.14609568.1999.00621.x

Baron-Cohen, S., Ring, H., Wheelwright, S., Williams, S., Brammer, M., and Bullmore, E. (2006). fMRI of parents of children with Asperger Syndrome: a pilot study. Brain Cogn. 61, 122-130. doi: 10.1016/j.bandc.2005.12.011

Baron-Cohen, S., Wheelwright, S., Hill, J., Raste, Y., and Plumb, I. (2001b). The "Reading the Mind in the eyes" test revised version: a study with normal adults, and adults with Asperger Syndrome or High-Functioning autism. J. Child Psychol. Psychiatry 42, 241-252. doi: 10.1111/1469-7610.00715

Baron-Cohen, S., Wheelwright, S., Skinner, R., Martin, J., and Clubley, E. (2001a). The Autism-Spectrum Quotient (AQ): evidence from Asperger Syndrome/high-functioning autism, males and females, scientists and mathematicians. J. Autism Dev. Disord. 31, 5-17. doi: 10.1023/A:1005653411471

Basirat, A., Sato, M., Schwartz, J., Kahane, P., and Lachaux, J. (2008). Parietofrontal gamma band activity during the perceptual emergence of speech forms. Neuroimage 42, 404-413. doi: 10.1016/j.neuroimage.2008.03.063

Bellani, M., Calderoni, S., Muratori, F., and Brambilla, P. (2013a). Brain anatomy of autism spectrum disorders I. Focus on corpus callosum. Epidemiol. Psychiatr. Sci. 22, 217-221. doi: 10.1017/S2045796013000139

Bellani, M., Calderoni, S., Muratori, F., and Brambilla, P. (2013b). Brain anatomy of autism spectrum disorders II. Focus on amygdala. Epidemiol. Psychiatr. Sci. 22, 309-312. doi: $10.1017 /$ S2045796013000346

Benenson, J. F. (2003). Sex on the brain. Nature 424, 132-133. doi: $10.1038 / 424132 b$

Bentin, S., Allison, T., Puce, A., Perez, E., and McCarthy, G. (1996). Electrophysiological studies of face perception in humans. J. Cogn. Neurosci. 8, 551-565. doi: 10.1162/jocn.1996.8.6.551

Berman, J. I., Edgar, J. C., Blaskey, L., Kuschner, E. S., Levy, S. E., Ku, M., et al. (2016). Multimodal diffusion-MRI and MEG assessment of auditory and language system development in autism spectrum disorder. Front. Neuroanat. 10:30. doi: $10.3389 /$ fnana.2016.00030

Billeci, L., Sicca, F., Maharatna, K., Apicella, F., Narzisi, A., Campatelli, G., et al. (2013). On the application of quantitative EEG for characterizing autistic brain: a systematic review. Front. Hum. Neurosci. 7:442. doi: $10.3389 /$ fnhum.2013.00442

Brown, M. S., Singel, D., Hepburn, S., and Rojas, D. C. (2013). Increased glutamate concentration in the auditory cortex of persons with autism and first-degree relatives: a 1H-MRS study. Autism Res. 6, 1-10. doi: 10.1002/aur.1260

Buard, I., Rogers, S. J., Hepburn, S., Kronberg, E., and Rojas, D. C. (2013). Altered oscillation patterns and connectivity during picture naming in autism. Front. Hum. Neurosci. 7:742. doi: 10.3389/fnhum.2013.00742

Calderoni, S., Bellani, M., Hardan, A. Y., Muratori, F., and Brambilla, P. (2014). Basal ganglia and restricted and repetitive behaviours in Autism Spectrum Disorders: current status and future perspectives. Epidemiol. Psychiatr. Sci. 23, 235-238. doi: 10.1017/S2045796014000171

Carr, L., Iacoboni, M., Dubeau, M. C., Mazziotta, J. C., and Lenzi, G. L. (2003). Neural mechanisms of empathy in humans: a relay from neural systems for imitation to limbic areas. Proc. Natl. Acad. Sci. U.S.A. 100, 5497-5502. doi: 10.1073/pnas.0935845100

Casey, B. J., Epstein, J. N., Buhle, J., Liston, C., Davidson, M. C., Tonev, S. T., et al. (2007). Frontostriatal connectivity and its role in cognitive control in parent-child dyads with ADHD. Am. J. Psychiatry 164, 1729-1736. doi: 10.1176/appi.ajp.2007.06101754

Constantino, J. N. (2002). The Social Responsiveness Scale. Los Angeles, CA: Western Psychological Services.

Conti, E., Calderoni, S., Gaglianese, A., Pannek, K., Mazzotti, S., Rose, S., et al. (2016). Lateralization of Brain Networks and Clinical Severity in Toddlers with Autism Spectrum Disorder: a HARDI Diffusion MRI Study. Autism Res. 9, 382-392. doi: 10.1002/aur.1533

Corbetta, M., and Shulman, G. L. (2011). Spatial neglect and attention networks. Annu. Rev. Neurosci. 34, 569-599. doi: 10.1146/annurev-neuro-061010-113731

Courchesne, E., Carper, R., and Akshoomoff, N. (2003). Evidence of brain overgrowth in the first year of life in autism. JAMA 290, 337-344. doi: 10.1001/ jama.290.3.337

Courchesne, E., Karns, C. M., Davis, H. R., Ziccardi, R., Carper, R. A., Tigue, Z. D., et al. (2001). Unusual growth patterns in early life in patients with autistic disorder. An MRI study. Neurology 57, 245-254. doi: 10.1212/WNL.57.2.245
Dawson, G., Munson, J., Webb, S. J., Nalty, T., Abbott, R., and Toth, K. (2007). Rate of head growth decelerates and symptoms worsen in the second year of life in autism. Biol. Psychiatry 61, 458-464. doi: 10.1016/j.biopsych.2006.07.016

Dawson, G., Webb, S. J., Wijsman, E., Schellenberg, G., Estes, A., Munson, J., et al. (2005). Neurocognitive and electrophysiological evidence of altered face processing in parents of children with autism: implications for a model of abnormal development of social brain circuitry in autism. Dev. Psychopathol. (Summer) 17, 679-697. doi: 10.1017/s0954579405050327

Dawson, G., Webb, S., Schellenberg, G. D., Dager, S., Friedman, S., Aylward, E., et al. (2002). Defining the broader phenotype of autism: genetic, brain, and behavioral perspectives. Dev. Psychopathol. (Summer) 14, 581-611. doi: $10.1017 /$ s0954579402003103

Dell'Osso, L., Dalle Luche, R., and Maj, M. (2016). Adult autism spectrum as a transnosographic dimension. CNS Spectr. 21, 131-133. doi: $10.1017 /$ S1092852915000450

Fatemi, S. H. (2008). The hyperglutamatergic hypothesis of autism. Prog. Neuropsychopharmacol. Biol. Psychiatry 32, 911, author reply 912-913. doi: 10.1016/j.pnpbp.2007.11.004

Fatemi, S. H., Folsom, T. D., Kneeland, R. E., and Liesch, S. B. (2011). Metabotropic glutamate receptor 5 upregulation in children with autism is associated with underexpression of both Fragile X mental retardation protein and GABAA receptor beta 3 in adults with autism. Anat. Rec. (Hoboken). 294, 1635-1645. doi: 10.1002/ar.21299

Fatemi, S. H., Reutiman, T. J., Folsom, T. D., and Thuras, P. D. (2009). GABA(A) receptor downregulation in brains of subjects with autism. J. Autism Dev. Disord. 39, 223-230. doi: 10.1007/s10803-008-0646-7

Freitag, C. M. (2007). The genetics of autistic disorders and its clinical relevance: a review of the literature. Mol. Psychiatry 12, 2-22. doi: 10.1038/sj.mp.4001896

Frith, C. D., and Frith, U. (1999). Interacting minds-a biological basis. Science 286, 1692-1695. doi: 10.1126/science.286.5445.1692

Gerdts, J., and Bernier, R. (2011). The broader autism phenotype and its implications on the etiology and treatment of autism spectrum disorders. Autism Res. Treat. 2011:545901. doi: 10.1155/2011/545901

Ghosh, S. S., Tourville, J. A., and Guenther, F. H. (2008). A neuroimaging study of premotor lateralization and cerebellar involvement in the production of phonemes and syllables. J. Speech Lang. Hear. Res. 51, 1183-1202. doi: 10.1044/1092-4388(2008/07-0119)

Greimel, E., Schulte-Rüther, M., Kircher, T., Kamp-Becker, I., Remschmidt, H., Fink, G. R., et al. (2010). Neural mechanisms of empathy in adolescents with autism spectrum disorder and their fathers. Neuroimage 49, 1055-1065. doi: 10.1016/j.neuroimage.2009.07.057

Hale, T. S., Smalley, S. L., Dang, J., Hanada, G., Macion, J., McCracken, J. T., et al. (2010). ADHD familial loading and abnormal EEG alpha asymmetry in children with ADHD. J. Psychiatr. Res. 44, 605-615. doi: 10.1016/j.jpsychires.2009.11.012

Hickok, G., and Poeppel, D. (2007). The cortical organization of speech processing. Nat. Rev. Neurosci. 8, 393-402. doi: 10.1038/nrn2113

Hussman, J. P. (2001). Suppressed GABAergic inhibition as a common factor in suspected etiologies of autism. J. Autism Dev. Disord. 31, 247-248. doi: 10.1023/A:1010715619091

Ingalhalikar, M., Parker, W. A., Bloy, L., Roberts, T. P., and Verma, R. (2012). Using multiparametric data with missing features for learning patterns of pathology. Med. Image Comput. Comput. Assist. Interv. 15, 468-475. doi: 10.1007/978-3-642-33454-2_58

Itier, R. J., Latinus, M., and Taylor, M. J. (2006). Face, eye and object early processing: what is the face specificity? Neuroimage 29, 667-676. doi: 10.1016/j.neuroimage.2005.07.041

Jamal, W., Das, S., Maharatna, K., Kuyucu, D., Sicca, F., Billeci, L., et al. (2013). "Using brain connectivity measure of EEG synchrostates for discriminating typical and Autism Spectrum Disorder," in Neural Engineering (NER), 2013 6th International IEEE/EMBS Conference on, 6-8 Nov (San Diego, CA), 1402-1405.

Jerbi, K., Ossandon, T., Hamame, C. M., Senova, S., Dalal, S. S., Jung, J., et al. (2009). Task-related gamma-band dynamics from an intracerebral perspective: review and implications for surface EEG and MEG. Hum. Brain Mapp. 30, 1758-1771. doi: 10.1002/hbm.20750

Jeste, S. S., and Geschwind, D. H. (2014). Disentangling the heterogeneity of autism spectrum disorder through genetic findings. Nat. Rev. Neurol. 10, 74-81. doi: 10.1038/nrneurol.2013.278 
Kaiser, J. (2004). Hearing lips: gamma-band activity during audiovisual speech perception. Cereb. Cortex 15, 646-653. doi: 10.1093/cercor/bhh166

Kana, R. K., Uddin, L. Q., Kenet, T., Chugani, D., and Müller, R. A. (2014). Brain connectivity in autism. Front. Hum. Neurosci. 8:349. doi: $10.3389 /$ fnhum. 2014.00349

Kanner, L. (1943). Autistic disturbances of affective contact. Nervous Child 2, $217-250$.

Klein, K. J. K., and Hodges, S. D. (2001). Gender differences, motivation, and empathic accuracy: when it pays to understand. Pers. Soc. Psychol. Bull. 27, 720-730. doi: 10.1177/0146167201276007

Kleinhans, N. M., Muller, R. A., Cohen, D. N., and Courchesne, E. (2008). Atypical functional lateralization of language in autism spectrum disorders. Brain Res. 1221, 115-125. doi: 10.1016/j.brainres.2008.04.080

Knecht, S., Drager, B., Deppe, M., Bobe, L., Lohmann, H., Floel, A., et al. (2000). Handedness and hemispheric language dominance in healthy humans. Brain 123(Pt 12), 2512-2518. doi: 10.1093/brain/123.12.2512

Koczat, D. L., Rogers, S. J., Pennington, B. F., and Ross, R. G. (2002). Eye movement abnormality suggestive of a spatial working memory deficit is present in parents of autistic probands. J. Autism Dev. Disord. 32, 513-518. doi: 10.1023/A:1021246712459

Lai, M.-C., Lombardo, M., Suckling, J., Ruigrok, A., Chakrabarti, B., Ecker, C., et al. (2013). Biological sex affects the neurobiology of autism. Brain 136, 2799-2815. doi: 10.1093/brain/awt216

Lainhart, J. E., Bigler, E. D., Bocian, M., Coon, H., Dinh, E., Dawson, G., et al. (2006). Head circumference and height in autism: a study by the collaborative program of excellence in autism. Am. J. Med. Genet. A. 140, 2257-2274. doi: 10.1002/ajmg.a.31465

Lange, N., Dubray, M. B., Lee, J. E., Froimowitz, M. P., Froehlich, A., Adluru, N., et al. (2010). Atypical diffusion tensor hemispheric asymmetry in autism. Autism Res. 3, 350-358. doi: 10.1002/aur.162

Levy, S. E., Mandell, D. S., and Schultz, R. T. (2009). Autism. Lancet 374, 1627-1638. doi: 10.1016/S0140-6736(09)61376-3

Losh, M., Childress, D., Lam, K., and Piven, J. (2008). Defining key features of the broad autism phenotype. Am. J. Med. Genet. Part B. 147B, 424-433. doi: 10.1002/ajmg.b.30612

Mannerkoski, M., Heiskala, H., Raininko, R., Aberg, L., Sarna, S., Wirtavuori, K., et al. (2009). Brain magnetic resonance imaging of siblings from families with two or more children with learning or intellectual disabilities and need for full-time special education. Acta Radiol. 50, 437-445. doi: $10.1080 / 02841850902756524$

McFadden, K. L., Hepburn, S., Winterrowd, E., Schmidt, G. L., and Rojas, D. C. (2012). Abnormalities in gamma-band responses to language stimuli in firstdegree relatives of children with autism spectrum disorder: an MEG study. BMC Psychiatry 12:213. doi: 10.1186/1471-244X-12-213

Mesulam, M. M. (1990). Large-scale neurocognitive networks and distributed processing for attention, language, and memory. Ann. Neurol. 28, 597-613. doi: 10.1002/ana.410280502

Mostofsky, S. H., Powell, S. K., Simmonds, D. J., Goldberg, M. C., Caffo, B., and Pekar, J. J. (2009). Decreased connectivity and cerebellar activity in autism during motor task performance. Brain 132, 2413-2425. doi: 10.1093/brain/awp088

Narzisi, A., Muratori, F., Calderoni, S., Fabbro, F., and Urgesi, C. (2013). Neuropsychological profile in high functioning autism spectrum disorders. J. Autism Dev. Disord. 43, 1895-1909. doi: 10.1007/s10803-012$1736-0$

Ors, M., Lindgren, M., Blennow, G., and Rosén, I. (2002). Auditory event-related brain potentials in parents of children with specific language impairment. Eur. J. Paediatr. Neurol. 6, 249-260. doi: 10.1053/ejpn.2002.0607

Palmen, S. J. M. C., Hulshoff Pol, H. E., Kemner, C., Schnack, H. G., Durston, S., Lahuis, B. E., et al. (2005b). Increased gray matter volume in medication naive high-functioning children with autism spectrum disorder. Psychol. Med. 35, 561-570. doi: 10.1017/S0033291704003496

Palmen, S. J. M. C., Pol, H. E. H., Kemner, C., Schnack, H. G., Sitskoorn, M. M., Appels, M. C. M., et al. (2005a). Brain anatomy in non-affected parents of autistic probands: a MRI study. Psychol. Med. 35, 1411-1420. doi: $10.1017 /$ S0033291705005015

Peterson, E., Schmidt, G. L., Tregellas, J. R., Winterrowd, E., Kopelioff, L., Hepburn, S., et al. (2006). A voxel-based morphometry study of gray matter in parents of children with autism. Neuroreport 17, 1289-1292. doi: 10.1097/01.wnr.0000233087.15710.87

Piven, J., Palmer, P., Jacobi, D., Childress, D., and Arndt, S. (1997). Broader autism phenotype: evidence from a family history study of multipleincidence autism families. Am. J. Psychiatry 154, 185-190. doi: 10.1176/ajp.15 4.2.185

Plante, E. (1991). MRI findings in the parents and siblings of specifically languageimpaired boys. Brain Lang. 41, 67-80. doi: 10.1016/0093-934X(91)90111-D

Poissant, H., Rapin, L., and Mendrek, A. (2014). Intergenerational transmission offronto-parietal dysfunction during forethought in attention deficit/hyperactivity disorder: a pilot study. Psychiatry Res. 224, 242-245. doi: 10.1016/j.pscychresns.2014.08.011

Polk, T. A., Park, J., Smith, M. R., and Park, D. C. (2007). Nature versus nurture in ventral visual cortex: a functional magnetic resonance imaging study of twins. J. Neurosci. 27, 13921-13925. doi: 10.1523/JNEUROSCI.400107.2007

Rapin, L., Poissant, H., and Mendrek, A. (2014). Atypical activations of frontocerebellar regions during forethought in parents of children with ADHD. J. Atten. Disord. 18, 242-251. doi: 10.1177/1087054714524983

Retico, A., Giuliano, A., Tancredi, R., Cosenza, A., Apicella, F., Narzisi, A., et al. (2016). The effect of gender on the neuroanatomy of children with autism spectrum disorders: a support vector machine case-control study. Mol. Autism 7, 5. doi: 10.1186/s13229-015-0067-3

Retico, A., Tosetti, M., Muratori, F., and Calderoni, S. (2014). Neuroimaging-based methods for autism identification: a possible translational application? Funct. Neurol. 29, 231-239. doi: 10.11138/fneur/2014.29.4.231

Ring, H., Baron-Cohen, S., Williams, S., Wheelwright, S., Bullmore, E., Brammer, M., et al. (1999). Cerebral correlates of preserved cognitive skills in autism. A functional MRI study of Embedded Figures task performance. Brain 122, 1305-1315. doi: 10.1093/brain/122.7.1305

Rojas, D. C., Maharajh, K., Teale, P., and Rogers, S. J. (2008). Reduced neural synchronization of gamma-band MEG oscillations in first-degree relatives of children with autism. BMC Psychiatry 8:66. doi: 10.1186/1471-244X-8-66

Rojas, D. C., Smith, J. A., Benkers, T. L., Camou, S. L., Reite, M. L., and Rogers, S. J. (2004). Hippocampus and amygdala volumes in parents of children with autistic disorder. Am. J. Psychiatry 161, 2038-2044. doi: 10.1176/appi.ajp.161.11.2038

Rojas, D. C., Teale, P. D., Maharajh, K., Kronberg, E., Youngpeter, K., Wilson, L. B., et al. (2011). Transient and steady-state auditory gamma-band responses in first-degree relatives of people with autism spectrum disorder. Mol. Autism 2:11. doi: $10.1186 / 2040-2392-2-11$

Rojas, D. C., and Wilson, L. B. (2014). $\gamma$-band abnormalities as markers of autism spectrum disorders. Biomark. Med. 8, 353-368. doi: 10.2217/bmm.14.15

Rommelse, N. N., Geurts, H. M., Franke, B., Buitelaar, J. K., and Hartman, C. A. (2011). A review on cognitive and brain endophenotypes that may be common in autism spectrum disorder and attention-deficit/hyperactivity disorder and facilitate the search for pleiotropic genes. Neurosci. Biobehav. Rev. 35, 1363-1396. doi: 10.1016/j.neubiorev.2011.02.015

Rossignol, D. A., Genuis, S. J., and Frye, R. E. (2014). Environmental toxicants and autism spectrum disorders: a systematic review. Transl. Psychiatry 4, e360. doi: 10.1038/tp.2014.4

Rubenstein, E., Wiggins, L. D., and Lee, L. C. (2015). A review of the differences in developmental, psychiatric, and medical endophenotypes between males and females with autism spectrum disorder. J. Dev. Phys. Disabil. 27, 119-139. doi: 10.1007/s10882-014-9397-x

Rubenstein, J. L., and Merzenich, M. M. (2003). Model of autism: increased ratio of excitation/inhibition in key neural systems. Genes Brain Behav. 2, 255-267. doi: 10.1034/j.1601-183X.2003.00037.x

Ruggeri, B., Sarkans, U., Schumann, G., and Persico, A. M. (2014). Biomarkers in autism spectrum disorder: the old and the new. Psychopharmacology (Berl). 231, 1201-1216. doi: 10.1007/s00213-013-3290-7

Seery, A. M., Vogel-Farley, V., Tager-Flusberg, H., and Nelson, C. A. (2013). Atypical lateralization of ERP response to native and non-native speech in infants at risk for autism spectrum disorder. Dev. Cogn. Neurosci. 5, 10-24. doi: 10.1016/j.dcn.2012.11.007

Segovia, F., Holt, R., Spencer, M., Górriz, J. M., Ramírez, J., Puntonet, C. G., et al. (2014). Identifying endophenotypes of autism: a multivariate approach. Front. Comput. Neurosci. 8:60. doi: 10.3389/fncom.2014.00060 
Shahin, A. J., Picton, T. W., and Miller, L. M. (2009). Brain oscillations during semantic evaluation of speech. Brain Cogn. 70, 259-266. doi: 10.1016/j.bandc.2009.02.008

Shinohe, A., Hashimoto, K., Nakamura, K., Tsujii, M., Iwata, Y., Tsuchiya, K. J., et al. (2006). Increased serum levels of glutamate in adult patients with autism. Prog. Neuropsychopharmacol. Biol. Psychiatry 30, 1472-1477. doi: 10.1016/j.pnpbp.2006.06.013

Sucksmith, E., Roth, I., and Hoekstra, R. A. (2011). Autistic traits below the clinical threshold: re-examining the broader autism phenotype in the 21st century. Neuropsychol. Rev. 21, 360-389. doi: 10.1007/s11065-011-9183-9

Sullivan, P. F., Kendler, K. S., and Neale, M. C. (2003). Schizophrenia as a complex trait: evidence from a meta-analysis of twin studies. Arch. Gen. Psychiatry 60, 1187-1192. doi: 10.1001/archpsyc.60.12.1187

Tick, B., Bolton, P., Happé, F., Rutter, M., and Rijsdijk, F. (2016). Heritability of autism spectrum disorders: a meta-analysis of twin studies. J. Child Psychol. Psychiatry 57, 585-595. doi: 10.1111/jcpp.12499

Turkeltaub, P. E., and Coslett, H. B. (2010). Localization of sublexical speech perception components. Brain Lang. 114, 1-15. doi: 10.1016/j.bandl.2010.03.008

Wagner, R. K., Togesen, J. K., and Rashotte, C. A. (1999). Comprehensive Test of Phonological Processing. Austin, TX: PRO-ED.
Wilson, L. B., Jason, R., Tregellas, J. R., Slason, E., Pasko, B. E., Hepburn, S., et al. (2013). Phonological processing in first-degree relatives of individuals with autism: an fMRI study. Hum. Brain Mapp. 34, 1447-1463. doi: 10.1002/hbm.22001

Witkin, H. A., Dyk, R. B., Faterson, H. F., Goodenough, D. G., and Karp, S. A. (1962). Personality Through Perception. New York, NY: Harper \& Row.

Yucel, G. H., Belger, A., Bizzell, J., Parlier, M., Adolphs, R., and Piven, J. (2014). Abnormal neural activation to faces in the parents of children with autism. Cereb. Cortex 25, 4653-4666. doi: 10.1093/cercor/bhu147

Conflict of Interest Statement: The authors declare that the research was conducted in the absence of any commercial or financial relationships that could be construed as a potential conflict of interest.

Copyright (C) 2016 Billeci, Calderoni, Conti, Gesi, Carmassi, Dell'Osso, Cioni, Muratori and Guzzetta. This is an open-access article distributed under the terms of the Creative Commons Attribution License (CC BY). The use, distribution or reproduction in other forums is permitted, provided the original author(s) or licensor are credited and that the original publication in this journal is cited, in accordance with accepted academic practice. No use, distribution or reproduction is permitted which does not comply with these terms. 